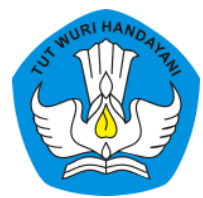

Page: 1-30

\title{
DESAIN DIDAKTIS PENJUMLAHAN DAN PENGURANGAN PECAHAN CAMPURAN DI SEKOLAH DASAR
}

\author{
Irfan Fauzi ${ }^{1} \&$ Ririn Arini ${ }^{2}$ \\ 1Sekolah Dasar Negeri 093 Tunas Harapan Cijerah, Bandung, Jawa Barat, Indonesia \\ ${ }^{2}$ Sekolah Dasar Negeri Panunggulan 2, Serang, Banten, Indonesia \\ ${ }^{1}$ Contributor Email: if96@upi.edu
}

Received: Jan 31, 2021

Accepted: Mar 10, 2021

Published: Mar 30, 2021

Article Url: https://ojsdikdas.kemdikbud.go.id/index.php/didaktika/article/view/225

\begin{abstract}
This research was motivated by the students' learning obstacle in understanding the addition and subtraction of mixed fractions. So this research aims to develop a didactic design on the addition and subtraction of mixed fractions in grade 5 elementary schools based on student learning trajectories and can improve students' learning obstacles on addition and subtraction of mixed fractions. This research used the Didactical Design Research (DDR) method in one of the elementary schools in Bandung, with the subjects being 30 students in grade 5 and 29 students in grade 6 . The data collection techniques used tests, interview, document analysis, focus group discussion (FGD), and observation. The results of this research indicated that the Didactic Design has a positive impact on student understanding and reduces the students' learning obstacles which are ontogenic, epistemological and didactical on the addition and subtraction of mixed fractions. Then, the average score of the students after the didactic design implementation was 75.3. This research is expected to be a reference for teachers in developing didactic designs for learning mathematics, especially fraction material in elementary schools using Didactical Design Research (DDR).
\end{abstract}

Keywords: Mixed Fractions, Learning Obstacle, Hypothethical Learning Trajectory 


\begin{abstract}
Abstrak
Penelitian ini dilatarbelakangi oleh hambatan belajar (learning obstacle) siswa dalam memahami penjumlahan dan pengurangan pecahan campuran. Penelitian ini bertujuan untuk mengembangkan desain didaktis penjumlahan dan pengurangan pecahan campuran di kelas 5 sekolah dasar sesuai dengan learning trajectory siswa dan dapat mengatasi learning obstacle pada materi pecahan campuran. Penelitian ini menggunakan metode Didactical Design Research (DDR) di salah satu sekolah dasar di Kota Bandung, dengan subjeknya adalah 30 siswa kelas 5 dan 29 siswa kelas 6. Teknik pengumpulan data menggunakan tes, wawancara, analisis dokumen, focus group discussion (FGD), dan observasi. Hasil Penelitian ini menunjukkan bahwa Desain Didaktis memberikan dampak positif terhadap pemahaman siswa dan mengurangi hambatan belajar siswa yang sifatnya ontogenic, epistemological dan didactical pada penjumlahan dan pengurangan pecahan campuran. Hasil rata-rata skor siswa setelah implementasi desain adalah 75,3. Penelitian ini diharapkan dapat menjadi referensi bagi guru dalam mengembangkan desain didaktis pembelajaran matematika khususnya materi pecahan di sekolah dasar dengan menggunakan Didactical Design Research (DDR).
\end{abstract}

Kata Kunci: Pecahan Campuran, Learning Obstacle, Hypothethical Learning Trajectory

\title{
A. Pendahuluan
}

Pendidikan matematika menjadi mata pelajaran yang sangat penting dari dulu (Bishop, 1998) sampai sekarang (Gravemeijer et al., 2017). Karenanya, wajar ketika matematika sudah diajarkan dari pendidikan dasar sampai pendidikan tinggi. Hal itu disebabkan matematika dapat mendorong siswa untuk memperoleh pengetahuan dan keterampilan yang dibutuhkan dalam kehidupan sehari-hari (Deringol, 2018). Bahkan, Freudenthal (1971) menyebutkan matematika sebagai aktivitas manusia sehingga setiap harinya manusia tidak akan lepas dari kegiatan matematik (Fauzi, 2020). Namun, faktanya banyak siswa yang kesulitan dalam pembelajaran matematika (Zening, 2017., Mullagin, 2011., \& Fathurrohman et al., 2018), bahkan cenderung menghindarinya (Mufarizuddin, 2018). Lebih parah lagi, sebagian siswa justru menganggap matematika merupakan pembelajaran yang sangat membosankan dan monoton, dan menyebabkan mereka emosi negatif 
seperti ketakutan, kecemasan dan kemarahan selama pembelajaran (Khiat, 2010). Kesulitan tersebut bukan hanya terjadi di sekolah dasar (Fauzi \& Suryadi, 2020a), tetapi juga terjadi di SMP (Novriani \& Surya, 2017), dan di SMA (Hadi et al., 2018). Dengan alasan tersebut, sudah seharusnya guru dapat menciptakan proses pembelajaran yang dapat mengatasi berbagai kesulitan siswa dengan cara mendorongnya pada minat belajar matematika karena itu adalah kunci keberhasilan siswa untuk ikut terlibat dan memahami pembelajaran matematika (Rellensmann \& Schukajlow, 2020).

Pecahan adalah salah satu materi yang mulai diajarkan di sekolah dasar (Fitri \& Prahmana, 2019), dan termasuk materi yang sulit dipahami siswa (Hoch et al., 2018., Loc, Tong \& Chau, 2017., \& Hansen, Mavrikis \& Geraniou, 2016). Bahkan menurut Hoch et al (2018) secara detail menjelaskan dalam penelitiannya, ada 33 penelitian internasional yang mengkaji dan menganalisis tentang pecahan dan menemukan 58 kesalahan yang dilakukan siswa. Kesalahan itu bersifat sistematis yaitu menerapkan sistem dan prosedur yang salah dan menunjukkan kurangnya pemahaman konseptual. Padahal pecahan sangat penting bagi siswa dan menjadi dasar dalam memahami materi yang lain seperti bilangan rasional, rasio dan perbandingan, desimal, persentase, dan probabilitas (Gabriel et al., 2013., \& Demiri, 2013). Berbagai buku dan artikel penelitian telah menganjurkan penekanan yang lebih besar pada pemahaman konseptual, terutama pemahaman konsep tentang pecahan (Lortie-Forgues, Tian \& Siegler, 2015). Menurut Barahmand (2020) mempelajari konsep pecahan adalah salah satu topik yang paling menantang dalam matematika sekolah.

Hambatan-hambatan yang dialami siswa dalam pembelajaran matematika khususnya pecahan perlu diantisipasi agar tidak muncul kembali. Salah satu hal penting yang harus dilakukan guru dalam tugas keprofesionalannya adalah mampu mengembangkan perencanaan pembelajaran (Ftriani, Muniarti \& Usman, 2017). Semakin matang 
perencanaan pembelajarannya, maka proses pembelajarannya akan berjalan dengan baik (Mayasari, 2020), dengan kata lain bahwa guru perlu merancang perencanaan pembelajaran yang sistematis, lengkap dan mengakomodasi berbagai kemungkinan hambatan belajar yang terjadi pada diri siswa (hypothethical learning obstacle) dan dapat mengantisipasinya (antisipasi didaktis-pedagogis). Faktanya, desain pembelajaran yang dibuat guru dalam proses pembelajaran dinilai tidak sesuai dengan kondisi nyata siswa (Saputri \& Mawardi, 2017), termasuk tingkat berpikirnya terutama di sekolah dasar yang masih pada tahap operasional konkret. Hal inilah yang menjadi alasan siswa kesulitan dalam memahami pembelajaran matematika. Seharusnya, guru dapat memperhatikan bahwa anak berpikir dengan cara yang sama sekali berbeda dengan orang dewasa (Ahmad, 2016).

Perencanaan pembelajaran perlu disusun dalam sebuah desain didaktis. Didactical Design Research (DDR) dipandang sebagai sebuah metode yang tepat dalam menyusun sebuah desain didaktis yang sesuai dengan kondisi nyata siswa dan dapat mengatasi hambatan belajarnya. Didactical Design Research (DDR) pertama kali diperkenalkan oleh Didi Suryadi (Guru Besar Matematika UPI) pada tahun 2010, dengan tujuan menciptakan sebuah formula yang tepat dalam upaya mengembangkan desain didaktis matematika. Menurut Suryadi (2018) DDR berpijak pada dua paradigma yaitu interpretif dan kritis. Paradigma tersebut menjadi dasar dalam menciptakan sebuah desain didaktis yang efektif dalam kegiatan pembelajaran.

Realitas yang dikaji dalam DDR berkaitan dengan karakteristik bayangan konsep yang terbentuk dalam diri seseorang sebagai dampak proses belajar dengan desain didaktis tertentu. Realitas bayangan konsep ini perlu dikaji karena manjadi bagian yang sangat penting dalam pendidikan matematika dan epistemologi matematika (Gerard, 1998). Proses pembentukan bayangan konsep matematika ini bukan hanya dialami oleh siswa saja sebagai subjek pembelajar, akan tetapi juga 
dialami oleh guru yang bertugas mengajarkan konsep pengetahuan kepada siswa. Bayangan konsep yang dimiliki guru sejatinya akan berdampak pada pemahaman dan pemaknaan siswa pada konsep pengetahuan yang dimilikinya. Bayangan konsep yang dimiliki siswa dan guru bisa jadi tidak sesuai dengan scientific conception yang sebenarnya, sehingga hal ini menjadi kajian realitas DDR untuk dapat menganalisis dan melihat kesesuaian Zone of Concept Image Different (ZCID) antara siswa, guru dan scientific conception. Selain itu, realitas lain yang menjadi kajian DDR ialah pada dampak desain didaktis yang mengakibatkan hambatan belajar atau learning obstacle pada siswa.

Kedua realitas yang telah dijelaskan di atas dapat memunculkan berbagai kemungkinan respon terkait hambatan belajar siswa dalam proses pembelajaran yang kemudian hal itu perlu disusun antisipasi didaktis pedagogis dalam suatu desain didaktis, sehingga desain didaktis yang dikembangkan dapat membentuk bayangan konsep yang sesuai dengan scientific conception dan dapat mengatasi learning obstacle yang dialami siswa, dengan dasar itulah paradigma interpretasi-kritis dapat digunakan dalam mendorong daya kreatif peneliti sehingga mampu memunculkan ide-ide terobosan untuk pengembangan desain didaktis yang lebih baik.

Penelitian ini bertujuan untuk mengembangkan sebuah desain didaktis pada penjumlahan dan pengurangan pecahan campuran di kelas 5 sekolah dasar. Penelitian yang menjelaskan terkait pengembangan desain pembelajaran pada materi pecahan adalah Nurjanah \& Leonard (2016) akan tetapi pengembangan desainnya hanya sampai pada tahap hipotesis, dan tidak diujicobakan, hal inilah yang menjadi kelemahan dari penelitian tersebut, padahal uji coba desain disini tujuannya untuk memperoleh gambaran secara nyata dari efektifitas desain yang telah dibuat.

Ada juga penelitian tentang pengembangan desain pada pembelajaran matematika yang menggunakan berbagai pendekatan/metode seperti Realistic Mathematics Education (Warsito, Nuraini \& Sukirwan, 2019), 
Etnomatematika (Rismawati, Suhendri \& Zulkarnain, 2019), kooperatif (Yusri \& Arifin, 2018), dan yang lainnya.

Secara umum, penelitian-peneltian yang telah dilakukan tersebut melalui berbagai tahapan seperti analisis berbagai kebutuhan, implementasi, dan evaluasi. Adapun yang menjadi perbedaan dengan penelitian ini adalah desain didaktis yang dikembangkannya pada materi penjumlahan dan pengurangan pecahan campuran yang didasarkan pada bayangan konsep dan learning obstacle yang ditemukan, dan dilengkapi dengan alur belajar (learning trajectory) yang dilalui siswa. Penelitian ini nantinya dapat memfasilitasi siswa untuk memahami penjumlahan dan pengurangan pecahan campuran secara utuh dan menyeluruh sesuai dengan learning trajectory siswa dan tanpa mengalami learning obstacle yang ditemukan sebelumnya. Desain didaktis yang dikembangkan pada penelitian ini melalui tahapan yang lengkap mulai dari perencanaan, implementasi, dan evaluasi dengan mengacu pada tahapan Didactical Design Research (DDR) yang merupakan sebuah metode design research khususnya dalam pendidikan matematika. Penelitian ini diharapkan dapat memberikan referensi bagi guru dalam merencanakan, melaksanakan dan mengevaluasi pembelajaran matematika pada materi penjumlahan dan pengurangan pecahan campuran di sekolah dasar.

\section{B. Metode}

Penelitian ini menggunakan metode studi kasus dan didactical design research (DDR). Menurut Gall et al (1999) studi kasus dilakukan untuk menjelaskan fenomena tertentu, seperti individu, program, proses, dan sebagainya. Penelitian studi kasus sangat cocok untuk mengkaji secara detail realitas dalam DDR terkait bayangan konsep dan learning obstacle siswa pada penjumlahan dan pengurangan pecahan campuran.

Bayangan konsep dan learning obstacle yang ditemukan pada penelitian ini menjadi dasar dalam pembuatan hypothetical learning trajectory dan pengembangan desain didaktis penjumlahan dan 
pengurangan pecahan campuran di kelas 5 sekolah dasar. Desain yang telah dikembangkan kemudian diimplementasikan untuk melihat dampaknya terhadap proses pembelajaran, sehingga tahap akhirnya adalah melakukan refleksi dan revisi terhadap desain didaktis penjumlahan dan pengurangan pecahan di kelas 5 sekolah dasar.

Pengembangan desain didaktis pada penelitian ini mengacu pada tahapan DDR yang terdiri dari tiga tahapan, yaitu (1) analisis situasi didaktis sebelum pembelajaran (analisis perspektif) yang wujudnya berupa desain didaktis hipotesis dan antisipasi didaktis pedagogis (ADP). Desain didaktis hipotesis yang dikembangkan pada penelitian ini dilengkapi dengan hypothetichal learning obstacle. Hal ini perlu dibuat untuk melihat berbagai kemungkinan hambatan belajar siswa yang terjadi selama pembelajaran, sehingga antisipasi didaktis pedagogis (ADP) perlu dibuat agar hambatan tersebut bisa diatasi dengan baik. Desain didaktis ini juga dilengkapi dengan hypothetichal learning trajectory siswa pada pembelajaran penjumlahan dan pengurangan pecahan campuran yang dijadikan pedoman dalam melaksanakan pembelajaran di kelas; (2) analisis situasi didaktis-pedagogis atau analisis metapedadidaktis. Analisis ini dilakukan ketika implementasi desain didaktis. Guru perlu mengembangkan tindakan didaktis sehingga tercipta situasi didaktis dan pedagogis yang sesuai dengan siswa, mengidentifikasi serta menganalisis berbagai respon siswa sebagai akibat tindakan didaktis maupun pedagogis, dan melakukan tindakan didaktis dan pedagogis lanjutan berdasarkan hasil analisis respon siswa. Hal ini dilakukan agar tujuan pembelajaran dapat tercapai; dan (3) Analisis retrospektif yang mengaitkan hasil analisis situasi didaktis hipotesis dengan hasil metapedadidaktis. Esensi dari retrospektif disini adalah menganalisis kesesuaian antara perencanaan dan implementasi desain didaktis yang nantinya dijadikan sebagai refleksi dan evaluasi desain didaktis.

Penelitian ini dilakukan di salah satu sekolah dasar di Kota Bandung, dengan subjeknya adalah 30 siswa kelas 5 dan 29 siswa kelas 6 . 
Teknik pengumpulan datanya adalah (1) tes, diberikan kepada siswa kelas 6 dengan tujuan memperoleh gambaran awal terhadap learning obstacle yang muncul berkiatan dengan penjumlahan dan pengurangan pecahan campuran. Tes juga diberikan kepada siswa kelas 5 yang sudah mendapatkan implementasi desain didaktis dengan tujuan untuk melihat dampak desain didaktis tersebut terhadap pemahaman siswa; wawancara, dilakukan kepada siswa untuk mengungkap secara detail bayangan konsep dan pola pikir atau alasan siswa dalam memberikan jawaban pada soal. Wawancara juga dilakukan kepada guru untuk melihat bayangan konsep pemahamannya terhadap penjumlahan dan pengurangan pecahan campuran dan cara guru mengajarkan materi tersebut; (3) analisis dokumen, buku ajar dijadikan sebagai dokumen yang dinalisis untuk melihat kesesuaian penyajian materi dengan kebutuhan siswa berdasarkan teori filosofis-pedagogis matematika; (4) focus group discussion (FGD), dilakukan ketika desain didaktis telah dibuat. FGD dilakukan bersama dengan dosen ahli dan guru yang mengajar kelas 5 . Tujuannya adalah untuk memperoleh masukan dan saran terkait desain didaktis berdasarkan theoritical knowledge dan practical knowledge sehingga harapannya desain yang dibuat sesuai dengan scientific conception; dan (5) observasi, dilakukan untuk melihat kesesuaian antara perencanaan dan implementasi. Hal yang diobservasi adalah kegiatan yang dilakukan siswa, hal yang menjadi perhatian khusus, catatan keberhasilan, dan hal yang harus diperbaiki dan ditingkatkan dalam proses pembelajaran. Kegiatan observasi ini menjadi dasar dalam melakukan refleksi dan evaluasi terhadap desain didaktis.

Analisis data hasil tes dilakukan dengan mencatat seluruh respon siswa yang muncul, mengidentifikasi dan mengelompokkan berdasarkan hambatannya. Hasil wawancara dibuat transkrip wawancara, dibuat coding terhadap makna kalimat yang penting, dan dibuat kesimpulannya terhadap bayangan konsep yang terjadi pada siswa dan guru. A3) analisis dokumen dilakukan dengan mencatat dan menganalisis berbagai hal yang penting 
terkait dengan penyajian materi dalam buku ajar dan mengaitkannya dengan teori filosofis-pedagogis matematika. Focus group discussion (FGD), desain didaktis yang telah dibuat didiskusikan dengan beberapa ahli. Data yang diperoleh dari hasil diskusi disajikan dalam bentuk transkip hasil diskusi, setelah itu dicatat hal-hal penting dari para ahli yang menjadi masukan untuk desain didaktis revisi. Observasi, dilakukan dengan cara mengambil video dan foto terhadap kegiatan pembelajaran disertai dengan mencatat hal penting yang muncul, memberikan komentar dan penilaian terhadap hasil observasi yang telah dilakukan.

Alur penelitian ini dijelaskan pada gambar 1 di bawah ini.

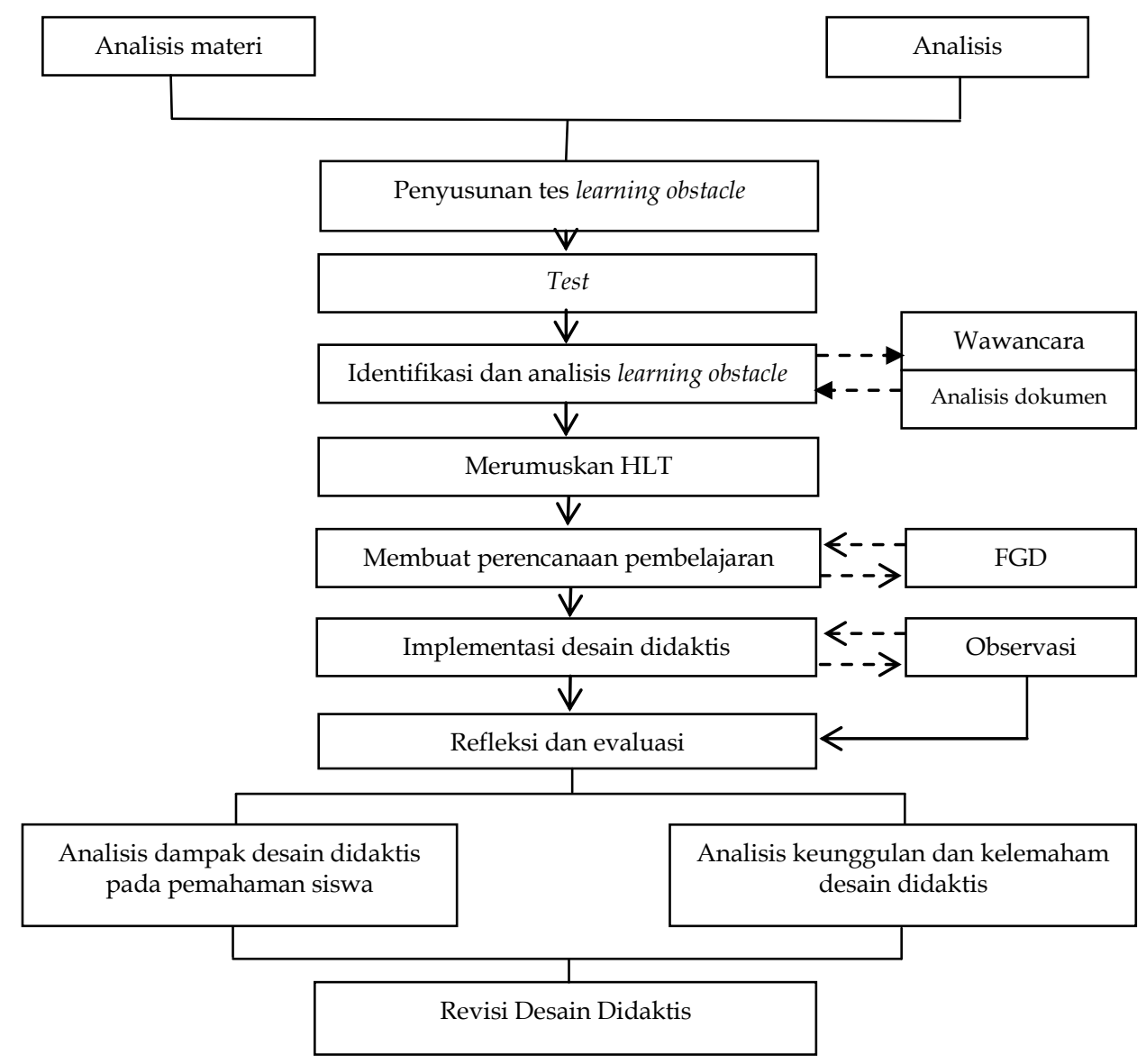

Gambar 1. Alur Penelitian 


\section{Hasil dan Pembahasan}

Hasil dan pembahasan pada penelitian ini diawali dengan mengungkap pengetahuan dan konsepsi matematika tentang penjumlahan dan pengurangan pecahan campuran yang terjadi baik yang dialami siswa maupun guru, dan analisis learning obstacle menjadi gambaran awal untuk mengungkap kedua hal tersebut, analisis learning obstacle menjadi dasar dalam mengembangkan hypothetical learning trajectory dan desain didaktis hipotesis. Hal itu kemudian diimplementasikan untuk melihat gambaran nyata dan dampak desain didaktis pada pemahaman siswa. Implementasi tersebut tentunya memberikan refleksi dan evaluasi terhadap perbaikan desain didaktis agar lebih baik.

Hasil pembahasan pada penelitian ini memfokuskan pada 3 hal yaitu learning obstacle siswa, hypothethical learning trajectory, dan desain didaktis penjumlahan dan pengurangan pecahan campuran. Menurut Brosseaou (2002) learning obstacle terbagi menjadi tiga yaitu (1) ontogenic obstacle, hambatan yang disebabkan karena adanya keterbatasan siswa yang berkaitan dengan pengembangan diri atau kesiapan mental siswa terhadap pembelajaran. Guru harus memahami batasan perkembangan intelektual siswa, hal ini penting sebagai dasar dalam pemberian konsep materi. Jika terlalu sulit akan berdampak pada hambatan belajar, tetapi jika terlalu mudah juga akan berpengaruh terhadap tingkat perkembangan intelektual mereka; (2) Epistemological obstacle, hambatan ini disebabkan keterbatasan pengetahuan siswa dalam memahami konteks materi yang diajarkan. Konteks epistemological di sini menitikberatkan pada pemahaman konsep yang dimiliki siswa yang tidak sesuai dengan scientific conception; dan (3) Didactical obstacle, hambatan yang terjadi pada siswa yang disebabkan pemahaman dan cara mengajar guru yang tidak sesuai. Bukan hanya itu saja, penyajian dalam buku ajar yang kurang tepat dinilai sebagai potensi penyebab siswa mengalami hambatan belajar.

Ontogenic obstacle yang terjadi pada siswa berkaitan dengan pembelajaran penjumlahan dan pengurangan pecahan campuran adalah 
ketidakmampuan siswa dalam memahami soal cerita yang bersifat nonroutine. Hal ini bisa dilihat pada gambar 2 di bawah ini.

7. Sebuah botol berisi air memiliki berat 20 ons, jika setengah airnya dibuang, maka berat botol
yang berisi air tersebut menjadi $11 \frac{3}{4}$ ons, berapakah berat botol tersebut jika tidak berisi air?
$20-11 \frac{3}{4}=\frac{20}{1}-\frac{47}{4}=\frac{80}{4}-\frac{47}{4}=\frac{33}{4}=8 \frac{1}{4}$ ons
$11 \frac{3}{4}=\frac{47}{4}$
Jadi berat botol tersebut jik0 tidak berisi air a dalab $8 \frac{1}{4}$ on

Gambar 2. Ontogenic obstacle

Berdasarkan gambar di atas, dapat diketahui bahwa siswa sudah memahami cara mengubah dari bilangan asli ke pecahan biasa, dan dari pecahan campuran ke pecahan biasa. Akan tetapi, siswa masih kebingungan dalam menyelesaikan soal di atas.

Berdasarkan hasil wawancara diketahui bahwa siswa menganggap bahwa untuk menyelesaikan soal di atas dengan cara langsung mengurangkan bilangan 20 dengan $11 \frac{3}{4}$, padahal 20 adalah berat botol jika berisi air penuh, sedangkan $11 \frac{3}{4}$ adalah botol jika airnya dibuang setengah. $20-11 \frac{3}{4}$ adalah cara untuk mengetahui berat setengah air yang dibuang, dan yang ditanyakannya adalah berat botol jika tidak berisi air. Seharusnya siswa dapat mengurangkan $11 \frac{3}{4}$ dengan $8 \frac{1}{4}$ (hasil pengurangan $20-11 \frac{3}{4}$ ) sehingga jawabannya adalah $3 \frac{1}{2}$ ons. Soal diatas diakui siswa sebagai soal yang tidak pernah mereka temui sebelumnya (non-routine), baik dari buku ataupun diberikan langsung oleh guru.

Beberapa penelitian juga menjelaskan bahwa siswa mengalami hambatan dalam menyelesiakan soal yang bersifat non-routine (Özcan, İmamoğlu \& Bayrakl1, 2017., \& Siniguian, 2017). Siswa biasanya hanya diberikan soal yang bersifat routine, pengerjaannya juga cenderung menerapkan cara yang sering guru ajarkan, dan bersifat imitatif (Jäder, Sidenvall \& Sumpter 2016., \& Mabilangan, 2011). Hal inilah yang 
mengakibatkan siswa mengalami hambatan ontogenic. Seharusnya guru dapat memberikan berbagai soal dari mulai yang routine sampai dengan yang non-routine. Menurut Zhang et al (2017) memecahkan soal nonroutine adalah salah satu keterampilan yang harus dimiliki siswa di abad 21, karena dalam memecahkannya menerapkan berbagai strategi alternatif dan melibatkan proses berpikir (Mahlios, 2014) termasuk berpikir kreatif (Fortes \& Andrade, 2019). Menurut Klymchuk (2014) memberikan soal non-routine akan bermanfaat untuk mempersiapkan siswa dalam menghadapi dunia nyata.

Epistemological obstacle yang muncul berkaitan dengan penjumlahan dan pengurangan pecahan campuran adalah ketidakmampuan siswa dalam mengubah berbagai bentuk pecahan dan mengoperasikannya. Hal ini bisa dilihat pada gambar 3 di bawah ini.

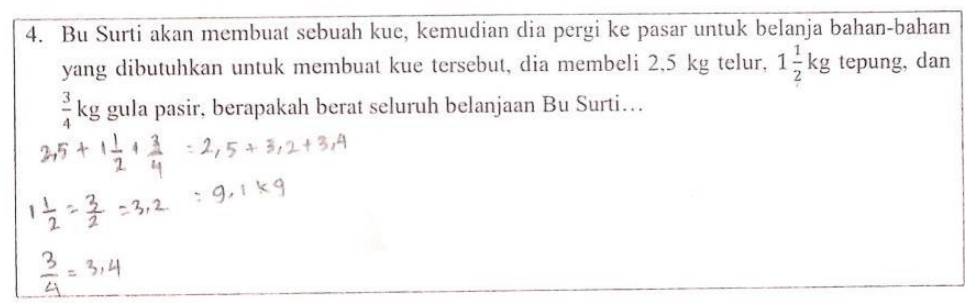

Gambar 3. Epistemological Obstacle 1

Berdasarkan gambar diatas, siswa mulai memahami pengubahan pecahan campuran ke pecahan biasa, akan tetapi yang menjadi masalah adalah pengubahan dari pecahan biasa ke pecahan desimal. Berdasarkan hasil wawancara siswa menggap bahwa pecahan biasa ketika diubah ke dalam bentuk desimal dapat dilakukan dengan menempatkan pembilang sebagai bilangan yang didepan koma, dan penyebut sebagai bilangan yang di belakang koma. Bisa dilihat dari gambar di atas $\left(\frac{3}{2}=3,2\right.$ dan $\left.\frac{3}{4}=3,4\right)$. Bukan hanya itu saja, beberapa siswa juga kesulitan dalam mengubah berbagai bentuk pecahan. Bisa dilihat pada gambar 4 di bawah ini. 


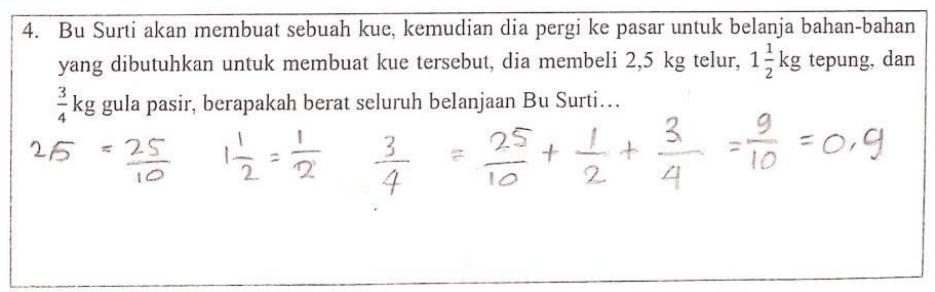

Gambar 4. Epistemological obstacle 2

Berdasarkan gambar di atas dapat diketahui bahwa siswa mengalami kesulitan dalam mengubah pecahan campuran ke pecahan biasa. Keslahan-kesalahan ini sering ditemukan dalam berbagai penelitian (Sari, Wibowo \& Kuriawan, 2019., \& Asminingsih, 2016).

Gambar di atas juga menunjukkan bahwa siswa masih mengalami kesulitan dalam mengoperasikan pecahan, artinya materi prasyaratnya belum mereka pahami secara benar. Kesulitan dalam mengoperasikan pecahan ini memang bukan sekali ini saja ditemukan, tetapi banyak penelitian juga menjelaskan hal yang sama terkait kesulitan tersebut (Fauzi \& Suryadi, 2020b., Tian \& Siegler, 2016., \& Fuchs et al, 2016). Kesalahan yang sering dilakukan siswa ini sifatnya adalah kesalahan konsep. Penyebab siswa kesulitan dalam mengoperasikan pecahan adalah mereka hanya menghafal rumus dan algoritma, bukan memahami makna pecahan itu sendiri (Şiap \& Duru, 2004., Gabriel et al, 2013).

Beberapa hambatan yang telah dijelaskan di atas bukan hanya dilatarbelakangi oleh siswa saja, akan tetapi bisa jadi karena pemahaman guru dan cara mengajarnya. Berdasarkan hasil wawancara bahwa guru hanya menyampaikan materi dalam buku ajar secara langsung kepada siswa, sehingga sumber informasinya hanya bersifat satu arah, dan siswa hanya sebagai pembelajar yang pasif seperti pad agambar 5 berikut ini.

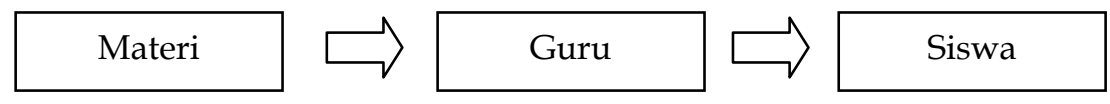

Gambar 5. Pemerolehan Informasi secara Linier 
Sudah seyogyanya guru dapat membangun pembelajaran dengan aktif dan komunikatif, bahkan siswa perlu dilibatkan dalam menemukan konsep pengetahuan yang dipelajari. Selain itu, guru juga mengakui bahwa proses pemberian tugas kepada siswa hanya bersifat routine dengan alasan bahwa ketika diberikan soal yang bentuknya cerita atau yang sifatnya non-routine siswa akan mengalami kesulitan dalam memahami konteks soal tersebut. Sebenarnya ini memang sering terjadi pada siswa terutama di sekolah dasar. Ini adalah hal yang biasa, ketika siswa diberikan soal yang sulit maka akan terjadi disequilibrium, dimana siswa harus memahami konteks masalah melalui informasi dan pengalaman baru (Lovatt \& Hedges, 2014), sehingga dampaknya siswa mengalami kesulitan dan kebingungan dalam menghadapi kondisi tersebut.

Menurut Aamaas, Duesund \& Lauritzen (2017) potensi anak terletak pada apa yang belum bisa dilakukan, dan hal tersebut bisa dicapai dengan dukungan atau bimbingan. Untuk mengatasi hal tersebut dibutuhkan peran scaffolding. Scaffolding di sini diartikan sebagai pemberian bantuan kepada siswa di awal pembelajaran, kemudian mengurangi bantuan tersebut agar siswa dapat mengambil alih tanggung jawab untuk menyelesaikan masalahnya secara mandiri (Baxter \& Williams, 2010). Scaffolding merupakan bagian dari strategi pembelajaran untuk memfasilitasi siswa agar dapat belajar secara efektif (Lin et al., 2017). Ketika peran scaffolding berjalan dengan baik, siswa akan mengalami equilibrium atau keseimbangan dalam memahami konteks masalah tertentu, dan di sinilah proses belajar terjadi.

Ketika dihadapkan pada operasi pecahan yang penyebutnya berbeda, guru menginstruksikan untuk menyamakan penyebutnya dengan mencari menggunakan KPK. Di sinilah proses pembentukan pengetahuan dibangun secara tidak lengkap yang akhirnya membuat siswa bingung dan mengalami kesulitan. Seharusnya pemahaman operasi pecahan yang berpenyebut berbeda harus dimulai dari esensi kenapa 
penyebutnya harus disamakan. Salah satu contoh yang bisa dilakukan guru adalah membuat representasi gambar yang berbentuk pecahan berpenyebut berbeda. Bisa dilihat dari gambar 6 berikut ini.

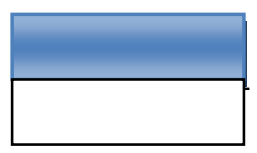

$\frac{1}{2}+\frac{1}{3}=$

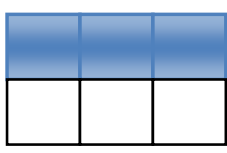

$\frac{3}{6}$

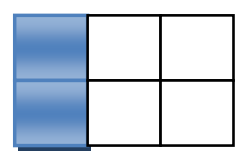

$\frac{2}{6}=\frac{5}{6}$

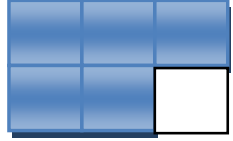

Gambar 6. Proses Awal Pembentukan Pemahaman Operasi Pecahan

Ketika konsep di atas sudah dibangun secara detail dan jelas, maka setelah itu baru dikuatkan dengan operasi pecahan menggunakan cara menyamakan penyebut pecahan dengan KPK. Sebetulnya, banyak guru di sekolah dasar yang tidak memiliki pemahaman utuh dalam hal mengurutkan, mengoperasikan, dan menjelaskan penghitungan pecahan (Namkung \& Fuchs, 2019). Inilah yang menjadi tugas guru untuk memperbaikinya.

Selain wawancara dengan guru, buku tes juga dianalisis untuk melihat penyajian materi yang diberikan kepada siswa, buku teks sangat berperan penting dalam proses belajar mengajar (Guantar, 2017). Analisis buku ajar tersebut didasarkan pada teori filosofis pedagogis matematika. Menurut Suryadi (2018) setiap manusia tidak terlepas dari aksi fisik (physical acts) dan aksi mental (mental acts). Karena itu, dalam proses pembelajarannya perlu dilibatkan kedua hal tersebut, akan tetapi dalam melibatkannya perlu diperhatikan bagaimana kedua hal tersebut dapat merangsang pembentukan pemahaman atau ways of understanding (WoU), dan cara berpikir atau ways of thingking (WoT). Hubungan ini disebut dengan Tradic (mental acts-WoU-WoT) (Harel, 2008). Model Tradic ini menjadi dasar munculnya gagasan dan terobosan baru tentang definisi matematika yang bersifat pedagogis, hal ini penting untuk menjawab pertanyaan filosofi 'apa itu matematika'. 
Berdasarkan analisis dalam buku ajar, tidak terdapat aksi fisik. Kegiatan instruksi yang terdapat dalam buku ajar hanya sebatas menulis. Kegiatan ini bukan aksi fisik yang dapat membetuk WoT dan WoU. Sementara itu, aksi mental dalam buku ajar hanya sebatas bagaimana siswa mencari jawaban dari masalah yang diberikan. Jawaban tersebut bahkan telah dipandu pada hasil yang mereka cari. Terlihat pada gambar 7 di bawah ini.

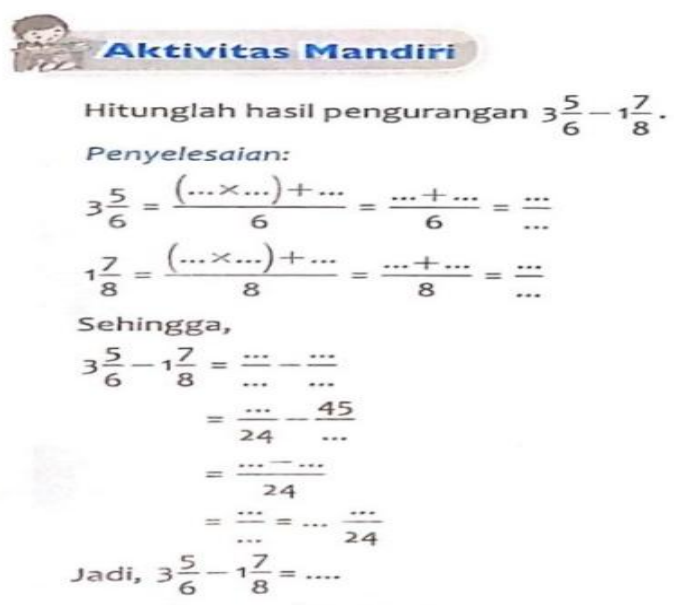

Gambar 7. Aksi Mental dalam Buku Ajar

Gambar diatas menunjukkan bahwa aksi mental yang dibentuk dalam buku ajar sama sekali tidak membentuk WoT dan WoU. Cara belajar seperti ini hanya akan membentuk ingatan jangka pendek (short time memory) pada siswa. Inilah yang menjadi salah satu penyebab terjadinya hambatan belajar pada siswa.

Learning obstacle yang terjadi menjadi dasar dalam penyusunan Hypothetical learning trajectory (HLT), selain itu HLT juga didasarkan pada theoritical knowladge baik dalam kurikulum, buku, dan artikel jurnal. Hal ini untuk membentuk alur belajar yang lengkap yang nantinya bisa memfasilitasi siswa untuk belajar pecahan campuran dengan benar.

The National Research Council dalam Alajmi (2012) dalam memahami pecahan maka yang harus ada dalam buku teks adalah (1) 
memahami bagian; (2) pecahan senilai; penggunaan model-model dan garis bilangan; (3) mengoperasikan pecahan; (4) memahami ukuran relatif dari pecahan; (5) perbandingan pecahan dan penyelesaian masalah; dan (6) menghubungkan pecahan dengan kehidupan sehari-hari siswa.

Materi pecahan campuran di kelas 5 termasuk ke dalam mengoperasikan pecahan, dan hal tersebut menjadi kemampuan yang harus dimiliki siswa di sekolah dasar. Adapun kompetensi minimal dalam kurikulum yang harus dimiliki siswa adalah melakukan dan menyelesaikan masalah terkait penjumlahan dan pengurangan pecahan yang berpenyebut berbeda.

Secara teori, materi pecahan campuran merujuk pada buku Iulia \& Gugoiu (2006) yang berjudul "The Book of Fraction". Ada beberapa hal yang perlu diperhatikan dalam pecahan campuran, yaitu bagaimana mengubah berbagai bentuk pecahan agar memudahkan pengoperasiannya. Pengubahan pecahan campuran dapat dilakukan dengan menggunakan cara $\left(W \frac{n}{d}=\frac{(d \times w)+n}{d}\right)$, atau untuk mengubah pecahan biasa ke pecahan campuran dapat dilakukan dengan membagi pembilang dengan penyebut, hasil bagi tersebut adalah bilangan asli dan sisa dari bagiannya adalah pembilang pecahan. Contohnya adalah $\frac{7}{2^{\prime}}, 7$ dibagi 2 sama dengan 3 , dan sisa bagiannya adalah 1 . Maka $\left(\frac{7}{2}=3 \frac{1}{2}\right)$.

Pecahan yang berpenyebutnya berbeda, terlebih dahulu harus disamakan penyebutnya agar pecahan tersebut dapat dioperasikan. Sama halnya pada pecahan campuran, ketika penyebutnya berbeda, maka harus disamakan terlebih dahulu. Jika penyebutnya sudah sama maka bisa langsung dipoerasikan. Adapun dalam penjumlahan caranya adalah $W 1 \frac{n 1}{d}+W 2 \frac{n 2}{d}=(W 1+W 2)\left(\frac{n 1+n 2}{d}\right)$, sama halnya dengan pengurangan $W 1 \frac{n 1}{d}-W 2 \frac{n 2}{d}=(W 1-W 2)\left(\frac{n 1-n 2}{d}\right)$.

Secara sederhana alur belajar yang dilalui siswa digambarkan sebagai berikut. 


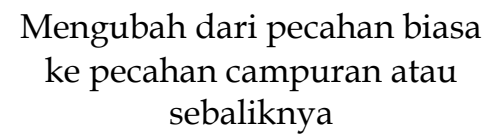

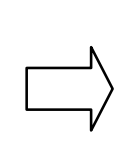

Menjumlahkan dan mengurangkan pecahan campuran

\section{Gambar 8. Alur Belajar}

Desain didaktis penjumlahan dan pengurangan pecahan campuran ini didasarkan pada tahapan didactical design research. Penyusunan desain didaktis penjumlahan dan pengurangan pecahan campuran ini didasarkan pada learning obstacle dan hypothetical learning trajectory siswa sebelumnya. Pada penyusunan ini, peneliti melakukan kajian terhadap pencapaian kompetensi dalam kurikulum, menyesuaikan dengan alur belajar, menyusun lesson plan berikut dengan perangkatnya. Desain yang telah disusun kemudian diberikan kepada guru yang sudah beberapa tahun mengajar untuk mendapatkan masukan secara practical experience terkait konteks pembelajaran yang diberikan siswa. Selain itu, desainnya juga diberikan kepada dosen ahli untuk mendapatkan masukan secara theoritical knowladge terkait konten yang disusun dalam desain tersebut. Melalui focus group discussion ini, beberapa hal menjadi catatan penting yang harus diperbaiki, di antaranya adalah penyajian konteks soal yang diberikan siswa dan cara mengajar. Catatan tersebut menjadi dasar dalam perbaikan desain didaktis.

Pembelajaran pada desain didaktis diawali dengan mengoperasikan pecahan yang berpenyebut berbeda. Hal ini dilakukan untuk menjembatani siswa agar memahami pengubahan pecahan biasa ke pecahan campuran. Konsep ini kemudian diperkuat dengan konsep pengubahan pecahan campuran ke pecahan biasa sehingga pemahaman siswa dapat menyeluruh. Setelah konsep itu dipahami, baru kemudian siswa diberikan konteks masalah penjumlahan dan pengurangan pecahan campuran.

Desain didaktis yang disusun juga dilengkapi dengan hypothetical learning obstacle yang mungkin terjadi pada siswa. Adapun kemungkinan tersebut dijelaskan pada tabel di bawah ini. 
Tabel 1. Hypothetical Learning Obstacle dan Antisipasi Didaktis-Pedagogis

\begin{tabular}{|c|c|c|}
\hline No & Hypothetical learning obstacle & Antisipasi didaktis-pedagogis \\
\hline 1. & $\begin{array}{l}\text { Siswa kesulitan dalam mengope- } \\
\text { rasikan pecahan dengan penyebut } \\
\text { berbeda }\end{array}$ & $\begin{array}{l}\text { Meminta siswa untuk melihat } \\
\text { kembali prosedur sebelumnya, } \\
\text { dan mengingatkan bahwa dalam } \\
\text { mengoperasikan pecahan penye- } \\
\text { butnya harus sama (bisa dengan } \\
\text { pecahan senilai atau mencari } \\
\text { KPK) }\end{array}$ \\
\hline 2. & $\begin{array}{l}\text { Siswa kesulitan dalam menyatakan } \\
\text { sebuah gambar ke dalam bentuk } \\
\text { pecahan atau sebaliknya }\end{array}$ & $\begin{array}{l}\text { Mengilustrasikan pembagian } \\
\text { pecahan yang lebih konkret, } \\
\text { seperti halnya mencontohkan } \\
\text { pembagian } 1 \text { kue yag dibagi } \\
\text { menjadi } 4 \text { bagian. Maka akan } \\
\text { menghasilkan pecahan } \frac{4}{4}\end{array}$ \\
\hline 3. & $\begin{array}{l}\text { Siswa kesulitan mencari hubungan } \\
\text { dari pengubahan pecahan biasa ke } \\
\text { pecahan campuran atau sebaliknya }\end{array}$ & $\begin{array}{l}\text { Meminta siswa untuk berdiskusi } \\
\text { dengan temannya, agar } \\
\text { menemukan hubungan antara } \\
\text { pecahan campuran dan pecahan } \\
\text { biasa }\end{array}$ \\
\hline 5. & $\begin{array}{l}\text { Siswa kesulitan dalam mengope- } \\
\text { rasikan pecahan campuran }\end{array}$ & $\begin{array}{l}\text { Meminta siswa untuk melihat } \\
\text { prosedur penyelesaian operasi } \\
\text { pecahan campuran }\end{array}$ \\
\hline
\end{tabular}

Pembelajaran diawali dengan memberikan siswa konteks masalah berkaitan dengan penjumlahan pecahan biasa. Adapun konteks masalah yang diberikan adalah sebagai berikut.

Andi membeli $\frac{3}{4} \mathrm{~kg}$ jeruk untuk dia makan, setelah itu ibunya memberikan jeruk kembali seberat $\frac{1}{2} \mathrm{~kg}$, berapakah berat keeluruhan jeruk tersebut?

Gambar 9. Kontes masalah penjumalahan pecahan berpenyebut berbeda

Dari konteks masalah di atas, siswa dapat menyelesaikan bahwa $\frac{3}{4}+\frac{1}{2}=\frac{5}{4}$. Tetapi beberapa siswa juga masih kesulitan dalam mengoperasikan pecahan, salah satu penyebabnya adalah tidak bisa perkalian dan pembagian, inilah yang menjadi menghambat bagi siswa dalam proses 
pembelajaran karena materi prasyaratnya belum dikuasai siswa secara penuh. Padahal perkalian dan pembagian adalah dasar semua perhitungan.

Hasil jawaban $\frac{5}{4}$ kemudian diminta untuk diubah ke dalam bentuk gambar. Hal ini bertujuan agar siswa dapat mengetahui secara jelas pengubahan pecahan biasa ke pecahan campuran. Awalnya beberapa siswa kebingungan untuk mengubahnya.

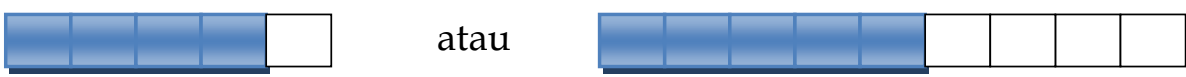

Gambar 10. Kekeliruan siswa dalam mengubah pecahan ke dalam gambar

Tetapi ada juga beberapa siswa yang mampu mengubahnya ke dalah bentuk gambar.

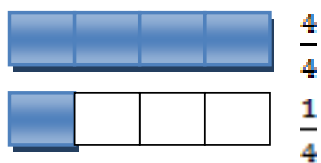

Gambar 11. Siswa Mampu Mengubah ke Dalam Bentuk Gambar

Guru menjelaskan bahwa pembagian pecahan pada gambar 9 di atas bukan $\frac{5}{4}$ tetapi itu adalah $\frac{4}{5}$ dan $\frac{5}{9}$. Siswa yang masih kebingungan tersebut diminta untuk memperhatikan ilustrasi bahwa pecahan terdiri dari bagian yang diamati dan bagian keseluruhan. Bagian yang diamati dari soal di atas adalah 5 bagian, sedangkan bagian keseluruhannya adalah 4 bagian. Guru memberikan contoh jika misalkan ada 1 kue di bagi ke dalam 4 bagian maka akan menghasilkan 4 bagian yang diamati dari 4 bagian keseluruhan atau $\frac{4}{4}$, dan yang ditanyakannya adalah $\frac{5}{4^{\prime}}$, artinya masih ada sisa $\frac{1}{4}$ bagian. Sehingga siswa memahami bahwa $\frac{5}{4}$ adalah $\frac{4}{4}+\frac{1}{4}$. Guru menstimulus siswa untuk menyadari bahwa $\frac{4}{4}$ adalah 1 , sehingga siswa diarahkan dapat menuliskan pecahan $\frac{5}{4}$ adalah $1+\frac{1}{4}$ atau $1 \frac{1}{4}$. 


\section{Irfan Fauzi \& Ririn Arini}

Setelah itu, guru meminta siswa untuk berdiskusi mencari hubungan dari $\frac{5}{4}$ dan $1+\frac{1}{4}$ atau $1 \frac{1}{4}$. Beberapa siswa menyadari bahwa untuk mengubah pecahan campuran ke pecahan biasa, maka yang harus diperhatikan adalah bilangan asli dan penyebut pecahannya. Contohnya adalah $3 \frac{1}{2}$ jika diubah ke pecahan biasa adalah $3+\frac{1}{2^{\prime}}$ maka yang diubahnya adalah bilangan asli dan memperhatikan penyebut pecahan $3+\frac{1}{2}=\frac{m}{2}+\frac{1}{2}$. Sehingga hasilnya adalah $\frac{6}{2}+\frac{1}{2}=\frac{7}{2}$. Konsep ini sangat penting diberikan siswa sebelum diarahkan pada cara langsung seperti $c_{b}^{a}=\frac{(b \times c)+a}{b}$.

Siswa kemudian diebrikan konteks masalah operasi penjumahan dan pengurangan pecahan campuran, adapun konteks yang diberikannya adalah sebagai berikut.

\begin{tabular}{|c|c|}
\hline $\begin{array}{l}\text { Bu Ana akan membuat kue, dia } \\
\text { membutuhkan bahan-bahan seperti } \\
\text { tepung seberat } 3 \frac{1}{4} \mathrm{~kg} \text {, dan telur } \\
\text { seberat } 1 \frac{1}{2} \text {. Berapakah berat bahan- } \\
\text { bahan tersebut }\end{array}$ & $\begin{array}{l}\text { Andi membeli } 2 \frac{1}{4} \mathrm{~kg} \text { jeruk, } \\
\text { kemudian dia memberikan } \frac{1}{2} \mathrm{~kg} \\
\text { jeruk kepada adiknya. Berapakah } \\
\text { berat jeruk yang dimiliki Andi } \\
\text { sekarang? }\end{array}$ \\
\hline
\end{tabular}

Gambar 12. Konteks Masalah Penjumalahan dan Pengurangan Pecahan Campuran

Dari konteks masalah tersebut dapat diketahui bahwa sebagian besar siswa mampu mengerjakan soal dengan benar. Siswa yang jawabannya benar melakukan cara bahwa dalam mengoperasikan pecahan yang penyebutnya berbeda, mereka menyamakan terlebih dulu penyebutnya. Sebelum itu siswa mengubah pecahan campuran di atas menjadi pecahan biasa agar mudah di operasikan. Ketika sudah sama penyebutnya, maka setelah itu mereka mengoperaskannya. Di samping itu, ada juga beberapa siswa yang masih keliru dalam perhitungan bahkan ada juga siswa yang masih kesulitan dalam pengubahan pecahan dan pengoperasian pecahan tersebut. 
Setelah siswa melakukan pembelajaran, guru memberikan evaluasi kepada siswa dengan memberikan beberapa soal terkait pengubahan pecahan campuran ke pecahan biasa atau sebaliknya dan operasi penjumlahan dan pengurangan pecahan campuran. Hasilnya menunjukkan dampak yang positif, rata-rata nilai siswa adalah 75,3. Adapun rekapitulasinya disajikan pada grafik di bawah.

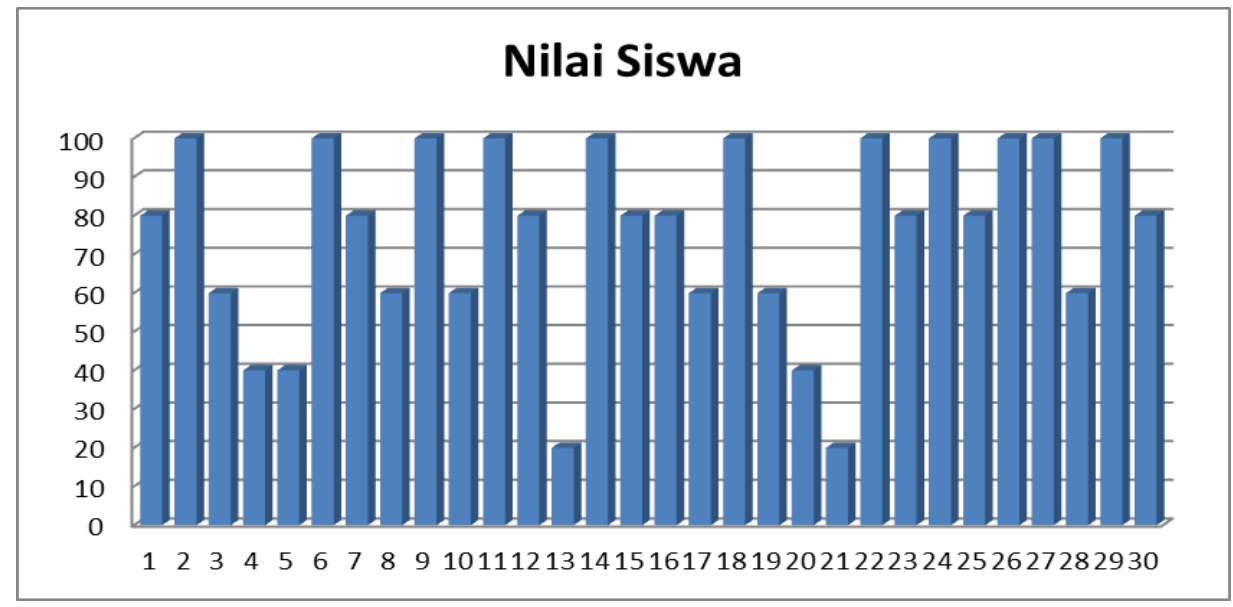

Grafik 1. Rekapitulasi nilai siswa

Berdasarkan hasil observasi bahwa siswa mulai memahami cara pengubahan bentuk pecahan dan mengoperasikan pecahan campuran sesuai dengan scientific conception, walaupun pada pembelajarannya masih ada beberapa siswa yang masih kebingungan dan kesulitan, hal yang menyebabkannya adalah karena siswa tidak menguasai materi prasyarat seperti perkalian bilangan dan KPK. Dalam mengajarkan konsep matematika, materi prasyarat harus dikuasai oleh siswa karena ini akan memudahkan mereka dalam memahami berbagai konsep dalam matematika. Sehingga siswa yang masih kesulitan dalam materi prasyarat pada desain didaktis penjumlahan dan pengurangan pecahan campuran ini adalah menjadi tugas guru untuk mengajarkannya secara benar.

Berdasarkan hasil penelitian di atas, bahwa hambatan belajar pasti dialami siswa dalam berbagai mata pelajaran khususnya dalam 
pembelajaran matematika, tentunya ini merupakan tugas guru untuk dapat mengantisipasinya melalui penyusunan desain didaktis yang sesuai dengan kebutuhan siswa.

Desain didaktis yang disusun ini dianggap memberikan dampak positif pada siswa dalam memahami operasi penjumlahan dan pengurangan pecahan campuran. Ada beberapa catatan yang melatarbelakanginya yaitu, desain didaktis mengakomodir berbagai kemungkinan hambatan belajar siswa, sehingga penyusunan antisipasi didaktis-pedagogis menjadi kunci keberhasilan dalam mengantisipasi berbagai hambatan belajar siswa tersebut. Kemudian, dalam desain tersebut proses pembelajarannya diberikan dengan melibatkan konteks masalah, siswa diminta untuk menyelesaikan masalah yang diberikan. Pandangan ini sesuai dengan teori Vygotsky tentang proses top-down (Kamil, 2010). Dengan memberikan konteks masalah, siswa dituntut untuk melakukan problem-solving, segingga mereka dapat menemukan apa yang mereka cari, dan membangun pengetahuannya secara mandiri.

Desain didaktis ini juga melibatkan interaksi antara siswa dengan siswa maupun dengan guru. Piaget (Müller, Eycke \& Baker, 2015) menjelaskan interaksi sosial sangat berpengaruh terhadap perkembangan kognitif siswa. Selain itu, bahkan dengan berinteraksi akan mengalami konflik kognitif yang mengarah pada munculnya akomodasi. Konflik kognitif merupakan keadaan dimana seseorang menyadari terkait perbedaan antara struktur kognitif dengan lingkungannya atau komponen-komponen lain seperti konsepsi, keyakinan, substruktur, dan lainnya dari kognitif seseorang (Lee et al., 2013). Dengan menyadari perbedaan yang dimiliki setiap individu, maka siswa akan termotivasi untuk terus melakukan diskusi sampai mereka menemukan titik temu dari perbedaan tersebut, dan di sinilah proses belajar terjadi.

Pada pembelajarannya, siswa juga mengalami disequilibrium sesuai yang dijelaskan sebelumnaya, akan tetapi setelah diberikan bimbingan baik melalui guru maupun teman sebaya, siswa mulai memahami (equilibrium) kontes pembelajaran penjumlahan dan pengurangan pecahan campuran. 


\section{Penutup}

Hasil penelitian ini menunjukkan bahwa desain didaktis penjumlahan dan pengurangan pecahan campuran memberikan dampak positif pada pemahaman siswa, hal ini bisa terlihat dari hasil evaluasi pembelajaran bahwa rata-rata nilai siswa adalah 75,3 siswa. Selain itu, desain ini juga mengurangi hambatan yang ditemukan sebelumnya berkaitan dengan ontogenic, epistemological, dan didactical obstacle pada materi penjumlahan dan pengurangan pecahan campuran. Desain didaktis yang telah diimplementasikan ini menjadi dasar bagi guru dalam mengajarkan penjumlahan dan pengurangan pecahan campuran. Sehingga hal ini dapat diterapkan dalam proses pembelajaran di kelas. Penelitian ini diharapkan dapat memberikan kontribusi nyata dalam dunia pendidikan khususnya dalam pendidikan matematika di sekolah dasar. Didactical design research (DDR) dapat digunakan menjadi salah satu alternatif metode dalam penyusunan desain didaktis matematika khususnya di sekolah dasar.

\section{Ucapan Terima Kasih}

Penulis mengucapkan terima kasih kepada salah satu instutusi sekolah dasar di Bandung yang telah memberikan izin penelitian kepada peneliti sehingga penelitian ini dapat disusun dengan baik. Selain itu, peneliti juga mengucapkan terima kasih kepada dosen ahli dan para guru yang berkenan untuk melakukan focus group discussion (FGD) yang membantu memberikan masukan berdasarkan theoritical knowladge dan practical experience untuk perbaikan desain didaktis yang disusun ini.

\section{Daftar Referensi}

Aamaas, Å., Duesund, K., \& Lauritzen, S. M. (2017). Placements Abroad and Scaffolding Structures. Studies in Higher Education, 1-15. https://doi.org/https://doi.org/10.1080/03075079.2017.1387106. 
Ahmad, S., Hussain, A., Batool, A., Sittar, K., \& Malik, M. (2016). Play and Cognitive Development: Formal Operational Perspective of Piaget's Theory. Journal of Education and Practice, 7(28), 72-79.

Alajmi, A. (2012). How Do Elementary Textbooks Address Fractions? A Review of Mathematics Textbooks in the USA, Japan, and Kuwait. Educational Studies in Mathematics, 79(2), 239-261. https://doi.org/10.1007/s10649-011-9342-1.

Asminingsih. (2016). Menggunakan Jigsaw untuk Meningkatkan Kompetensi Operasi Hitung Berbagai Bentuk Bilangan Pecahan di Kelas III SDN Baujeng 1 Ta 2012-2013. Jurnal Ilmiah Edukasi $\mathcal{E}$ Sosial, 7(2), 142-145.

Barahmand, A. (2020). Equivalent Fractions and Natural Number Bias. For the Learning of Mathematics, 40(3), 20-22.

Baxter, J.A., \&Williams, S. (2010). Social and Analytic Scaffolding in Middle School Mathematics: Managing The Dilemma of Telling. Journal of Mathematics Teacher Education, 13(1), 7-26. https://doi.org/10.1007/s10857-009-9121-4.

Bishop, A. (1998). Mathematical Enculturation: A Cultural Perspective on Mathematics Education. Dordrecht, Boston, London: Kluwer Academic Publisher.

Brosseaou, G. (2002). Theory of Didactical Situation in Mathematics. New York, Boston, Dordrecht, London, Moscow: Kluwer Academic Publishers.

Demiri, L. (2013). Researching Teachers and Pre-Service Teachers'knowledge of Students' Misconceptions about Fractions. Thesis, Marmara University Institute of Educational Sciences, Istanbul, Turkey.

Deringol, Y. (2018). Primary School Students' Mathematics Motivation and Anxieties. Cypriot Journal of Educational Sciences, 13(4), 537-548. https://doi.org/10.18844/cjes.v13i4.3462.

Fathurrohman, M., Rahayu, I., \& Nindiasari, H. (2009). Pengembangan Media Pembelajaran Untuk Menghindari Mind in Chaos. Jurnal Ilmu Pendidikan, 16(2), 106-111. http://dx.doi.org/10.17977/jip.v16i2.2562.

Fauzi, I. (2020). Desain Didaktis Penjumlahan dan Pengurangan Pecahan di Kelas 5 Sekolah Dasar. Thesis, Universitas Pendidikan Indonesia. 
Fauzi, I., \& Suryadi, D. (2020a). The Analysis of Students' Learning Obstacles on the Fraction Addition Material for Five Graders of Elementary Schools. Al Ibtida: Jurnal Pendidikan Guru MI, 7(1), 33 45. https:// doi.org/10.24235/al.ibtida.snj.v7i1.6020.

Fauzi, I., \& Suryadi, D. (2020b). Learning Obstacle the Addition and Subtraction of Fraction in Grade 5 Elementary Schools. Mudarrisa: Jurnal Kajian Pendidikan Islam, 12(1), 50-67. https://doi.org/10.18326/mdr.v12i1.50-67.

Fitri, N. L., \& Prahmana, R. C. I. (2019). Misconception in Fraction for Seventh-Grade Students. Journal of Physics: Conference Series, 1188 012031, 1-8. https://doi.org/10.1088/1742-6596/1188/1/012031.

Fitriani, C., Murniati, A. R., \& Usman, N. (2017). Kompetensi Profesional Guru dalam Pengelolaan Pembelajaran di MTs Muhammadiyah Banda Aceh. Jurnal Administrasi Pendidikan, 5(2), 88-95.

Fortes, E. C., \& Andrade, R. R. (2019). Mathematical Creativity in Solving Non-Routine Problems. The Normal Lights, 13(1), 108-135.

Freudenthal, H. (1971). Geometry between the Devil and The Deep Sea. Educational Studies in Mathematics, 3, 413-435.

Fuchs, L. S., Malone, A. S., Schumacher, R. F., Namkung, J., Wang, A. (2016). Fraction Intervention for Students with Mathematics Difficulties: Lessons Learned from Five Randomized Controlled Trials. Journal of Learning Disabilities, 50(6) 631-639. https://doi.org/10.1177/0022219416677249.

Gabriel, F., Coché, F., Szücs, D., Carette, V., Rey, B., \& Content, A. (2013). A Componential View of Children's Difficulties in Learning Fractions. Developmental Psychology, 715(4), 1-12. https://doi.org/10.3389/fpsyg.2013.00715.

Gall, M. D., Gall, J. P., \& Borg, W. R. (1999). Applying Educational Research: How to Read, Do, and Use Research (6th ed.). New York: Pearson.

Gerard, V. (1998). A Comprehensive Theory of Representation for Mathematics Education. The Journal of Mathematical Behavior, 17(2), 167-181. https:/ / doi.org/10.1016/S0364-0213(99)80057-3.

Gravemeijer, K., Stephan, M., Julie, C., Lin, F. L., \& Ohtani, M. (2017). What Mathematics Education May Prepare Students for the Society of the Future? International Journal of Science and Mathematics Education, 15, 
105-123. https:// doi.org/10.1007/s10763-017-9814-6.

Guantar, D. A. (2017). Textbooks Analysis: Analyzing English as a Foreign Language (EFL) Textbooks from the Perspective of Indonesian Culture. Language Circle: Journal of Language and Literature, 7(2), 173-182. https:/ / doi.org/10.15294/lc.v11i2.9590.

Hadi, S., Retnawati, H., Munadi, S., Apino, E., \& Wulandari, N. F. (2018).The Difficulties of High School Students in Solving HigherOrder Thinking Skills Problems. Problems of Education in The 21st Century, 76(4), 520-532.

Hansen, A., Mavrikis, M., \& Geraniou, E. (2016). Supporting Teachers' Technological Pedagogical Content Knowledge of Fractions Through Codesigning a Virtual Manipulative. Journal of Mathematics Teacher Education, 19(2), 205-226. https://doi.org/10.1007/s10857-016-9344-0.

Harel, G. (2008). What is Mathematics? A Pedagogical Answer to a Philosophical Question. In Gold, B \& Simons, R. (Eds.), Proof and Another Dilemmas. Mathematics and Philosophy (pp. 265-290). Washington: The Mathematical Association of America, Inc.

Hoch, S., Reinhold, F., Werner, B, Richter-Gebert, J \& Reiss, K. (2018). Design and Research Potential of Interactive Textbooks: The Case of Fractions. ZDM Matehematics Education, 50(5), 839-848. https://doi.org/10.1007/s11858-018-0971-z.

Ionescu, T., \& Vasc, D. (2014). Embodied Cognition: Challenges for Psychology and Education. Procedia-Social and Behavioral Sciences, 128, 275-280. https:// doi.org/10.1016/j.sbspro.2014.03.156.

Iulia \& Gugoiu, T. (2006). The Book of Fraction. Mississauga, Ontario, Canada: Albina Way.

Jäder, J., Sidenvall, J., \& Sumpter, L. (2016). Students' Mathematical Reasoning and Beliefs in Non-routine Task Solving. International Journal of Science and Mathematics Education, 15(4), 759-776. doi:10.1007/s10763-016-9712-3.

Kamil, M. (2010). Landasan Teori dalam Pengembangan Model Pembelajaran. Bandung: Universitas Pendidikan Indonesia.

Khiat, H. (2010). A Grounded Theory Approach: Conceptions of Understanding in Engineering Mathematics Learning. The Qualitative Report, 15(6), 1459-1488. 
Klymchuk, S. (2014). Provocative Mathematics Questions: Drawing Attention to a Lack of Attention. Teaching Mathematics and Its Applications, 34(2), 63-70. doi:10.1093/teamat/hru022.

Lee, G., Kwon, J., Park, S. S., Kim., J. W., Kwon, H. G., \& Park, C. K. (2013). Development of an Instrument for Measuring Cognitive Conflict in Secondary-Level Science Classes. Journal of Research in Science Teaching, 40(6), 585-603. https://doi.org/10.1002/ tea.10099.

Lin, T., Hsu, Y., Lin, S., Changlai, M., Yang, K., \& Lai, T. (2012). A Review of Empirical Evidence on Scaffolding for Science Education. International Journal of Science and Mathematics Education, 10, 437-455.

Loc, N. P., Tong, D. H., \& Chau, P. T. (2017). Identifying the Concept "Fraction" of Primary School Students: The Investigation in Vietnam. Educational Research and Reviews, 12(8), 531-539. https://doi.org/10.5897/ERR2017.3220.

Lortie-Forgues, H., Tian, J., \& Siegler, R. S. (2015). Why Is Learning Fraction and Decimal Arithmetic So Difficult?. Developmental Review, 38, 201-221. https:// doi.org/10.1016/j.dr.2015.07.008.

Lovatt, D., \& Hedges, H. (2014). Children's Working Theories: Invoking Disequilibrium. Early Child Development and Care, 185(6), 909-925. https://doi.org/10.1080/03004430.2014.967688.

Mabilangan, R. A. (2011). Problem Solving Strategies of High School Students on Non-routine Problems: An Exploratory Study. Thesis, Philippine Normal University.

Mahlios, J. (1988). Word Problems: Do I Add or Subtract? Arithmetic Teacher, 25(2), 16-20.

Mayasari, D. (2020). Program Perencanaan Pembelajaran Matematika. Sleman: CV Budi Utama.

Mufarizuddin. (2018). Analisis Kesulitan Pembelajaran Matematika Siswa Kelas 5 SD Negeri 012 Bangkinang Kota. Journal on Education, 1(2), 40-47.

Müller, Eycke \& Baker. (2015). Piaget's Theory of Intelligence in Goldstein, S., Princiotta, D., \& Naglieri, J. A. (Eds.). Handbook of Intelligence. https://doi.org/10.1007/978-1-4939-1562-0.

Mulligan, J. (2011). Towards Understanding the Origins of Children's Difficulties in Mathematics Learning. Australian Journal of Learning Difficulties, 16(1), 19-39. https://doi.org/10.1080/19404158.2011.563476. 
Namkung, J., \& Fuchs, L. (2019). Remediating Difficulty with Fractions for Students with Mathematics Learning Difficulties. Learning Disabilities: A Multidisciplinary Journal, 24(2), 36-48. https://doi.org/10.18666/LDMJ-2019-V24-I2-9902.

Novriany, M. R., Surya, E. (2017). Analysis of Student Difficulties in Mathematics Problem Solving Ability at MTs SWASTA IRA Medan. International Journal of Sciences: Basic and Applied Research (IJSBAR), 33(3), 63-75.

Nurjanah, D., \& Leonard. (2016). Pengembangan Desain Pembelajaran Matematika Kelas V Sekolah Dasar. Prosiding Seminar Nasional Pendidikan Matematika FTMIPA Unindra, 2, 525-534.

Özcan, Z. C., İmamoğlu, Y., \& Bayraklı, V. K. (2017). Analysis of Sixth Grade Students' Think-Aloud Processes While Solving a Nonroutine Mathematical Problem. Educational Science: Theory $\mathcal{E}$ Practice, $17(1)$, 129-144. http://dx.doi.org/10.12738/estp.2017.1.2680.

Rellensmann, J., \& Schukajlow, S. (2020). Does Students' Interest in a Mathematical Problem Depend on the Problem's Connection to Reality? An Analysis of Students' Interest and Pre-service Teachers' Judgments of Students' Interest in Problems with and without a Connection to Reality. ZDM, 49(3), 367-378. http://dx.doi.org/10.1007/s11858-016-0819-3.

Rismawati., Suhendri, H., \& Zulakrnain, I. (2019). Pengembangan Desain Pembelajaran Matematika Kelas V SD Berbasis Etnomatematika. Journal of Mathematics Education, Science and Tecnology, 4(2), 230-250. http://dx.doi.org/10.30651/must.v4i2.3201.

Sari, N., Wibowo, T., \& Kurniawan, H. (2019). Identifikasi Kesulitan Numerik Siswa dalam Mengaplikasikan Operasi Hitung Bilangan Pecahan. Seminar Nasional Matematika ke-11 Universitas Gadjah Mada, 60-72.

Şiap, İ, \& Duru, A. (2004). The Ability to Use Geometrical Models in Fractions. Kastamonu Education Journal, 12(1), 89-96. https://doi.org/10.11114/jets.v5i11.2679.

Siniguian, M. T. (2017). Students Difficulty in Solving Mathematical Problems. International Journal of Advanced Research in Engineering and Applied Sciences, 6(2), 1-12. 
Suratno, T. (2016). Didaktik dan Didactical Design Research. In Suryadi, D., Mulyana, E., Suratno, T., Dewi, D. A. K., \& Maudy. S.Y. (Eds.), Monograf Didactical Design Research. Bandung: Rizqi Press.

Suryadi, D. (2018). Landasan Filosofis Penelitian Desain Didaktis (DDR). Bandung: Departemen Pendidikan Matematika UPI.

Tian, J., Siegler, R. S. (2016). Fractions Learning in Children With Mathematics Difficulties. Journal of Learning Disabilities, 50(6), 614https://doi.org/620. 10.1177/0022219416662032.

Warsito, Nuraini \& Sukirwan (2019). Desain Pembelajaran Pecahan melalui Pendekatan Realistik di Kelas V. Mosharafa: Jurnal Pendidikan Matematika, 8(1), 25-36. https://doi.org/10.31980/mosharafa.v8i1.381.

Yusri, Y., \& Arifin, S. (2018). Desain Pembelajaran Kooperatif Berbasis Teori Bruner Untuk Meningkatkan Kualitas Pembelajaran Matematika. HISTOGRAM: Jurnal Pendidikan Matematika, 2(2), 147155. https://doi.org/10.31100/histogram.v2i2.233.

Zengin, Y. (2017). International Forum of Educational Technology \& Society Investigating the Use of the Khan Academy and Mathematics Software with a Flipped Classroom Approach in Mathematics Teaching Published by: International Forum of Educational Technology \& Society Inv. Journal of Educational Technoloy \& Society, 20(2), 89-100.

Zhang, L., Yu, S., Li, B., \& Wang, J. (2017). Can Students Identify the Relevant Information to Solve a Problem?. Educational Technology \& Society, 20(4), 288-299. 